\title{
AVALIAÇÃO AMBIENTAL COMPARATIVA DA FABRICAÇÃO DE DESTILADOR TRADICIONAL E MISTO PARA UTILIZAÇÃO NA PRODUÇÃO DE ETANOL EM PEQUENA ESCALA
}

\author{
M. BRONDANI ${ }^{1}$, R. HOFFMANN ${ }^{1}$ e F. D. MAYER ${ }^{2}$ \\ ${ }^{1}$ Universidade Federal de Santa Maria, Departamento de Engenharia Química \\ ${ }^{2}$ Universidade Federal do Rio Grande do Sul, Departamento de Engenharia Química \\ E-mail para contato: mbbrondani@gmail.com
}

\begin{abstract}
RESUMO - O Rio Grande do Sul (RS) produz pouco do etanol que consome, pois condições edafoclimáticas impedem a produção agrícola extensiva. Destilarias de pequeno porte podem fornecer este etanol, porém, estudos da Universidade Federal de Santa Maria (UFSM) apontaram déficit econômico e energético na produção de etanol hidratado em pequena escala devido ao diminuto rendimento das etapas de moagem e destilação. Uma coluna de destilação mista, com pratos e recheio, além de outras alterações construtivas e operacionais, foi investigada a fim de solucionar as desvantagens apresentadas pelas colunas tradicionais, abrindo espaço para o uso da Avaliação do Ciclo de Vida (ACV) para comparação ambiental da produção dessas colunas. O uso da ACV, realizada com o auxílio do software SimaPro ${ }^{\circledR}$, permitiu a comparação dos impactos ambientais da fabricação desses dois destiladores. O modelo de destilador tradicional apresentou maiores contribuições de impactos do que o modelo misto. Indica-se a escolha de uma coluna mista a fim de reduzir os impactos ambientais na produção de etanol.
\end{abstract}

\section{INTRODUÇÃO}

Enquanto que apenas $13 \%$ do total de energia primária mundial são obtidos de fontes renováveis (IEA, 2010), no Brasil essa parcela é, em média, de 47,2\% de acordo com BEN (2012). Desses 47,2\%, em média, 16,9\% é atribuído a produtos da cana-de-açúcar (produção de etanol e cogeração de energia elétrica).

Segundo UNICA (2013), o Brasil é o segundo maior produtor mundial de etanol, no entanto, alguns estados, como o Rio Grande do Sul, são deficitários na sua produção.

O RS produz menos de $2 \%$ do álcool que consome e paga um preço alto pela importação de álcool de outros estados (Castro et al., 2008). Condições edafoclimáticas impedem a produção agrícola extensiva e a consequentemente a instalação de grandes usinas no Estado. 
Nesse sentido, pequenas destilarias (microdestilarias) são alternativas para a produção de etanol, ainda que contrariando o panorama atual da agroindústria canavieira extensiva existente no Brasil. Para Ortega et al. (2008) quando se planeja ou se constrói uma destilaria de etanol, determina-se o futuro da região sendo que as escalas de produção de 4 até menos de 4.000 hectares podem produzir etanol hidratado (94\%), adubo e outros co-produtos, sem cogeração de eletricidade.

É também sabido que o rendimento nos processos em pequena escala pode ser ligeiramente inferior aos de grande escala, no entanto, não inviabiliza o processo. De acordo com estudos realizados na microdestilaria da Universidade Federal de Santa Maria (UFSM) há um déficit econômico e energético na produção de etanol a partir da cana-de-açúcar, em pequena escala, devido ao diminuto rendimento e eficiência de algumas etapas da produção do etanol hidratado, principalmente na etapa de destilação, que obteve valor abaixo do esperado.

Enquanto que a extração do caldo obteve rendimento inicial de 76,9\% (com redução para 60-65\%, a partir da utilização contínua), a etapa de fermentação obteve rendimento de $85 \%$, ambos dentro de valores aceitáveis para esta escala de processo. No entanto, a etapa de destilação resultou em rendimento de apenas 65\%, segundo UFSM (2010).

Esse problema pode ser esperado em outras microdestilarias instaladas ou a serem instaladas no RS. Visando minimizar tais percalços, está sendo realizado o estudo de utilização de uma coluna de destilação diferente da usual (coluna de destilação de pratos ou bandejas) por uma coluna tipo mista (coluna de pratos e recheio), além de outras alterações construtivas e operacionais, o que abriu espaço para aplicação da metodologia de Avaliação do Ciclo de Vida (ACV) na comparação ambiental da produção desses dois tipos de colunas de destilação.

Segundo Weidema e Meeusen (2000) e Mendonça (2007) a ACV é definida como uma técnica para determinar os potenciais impactos associados a um produto pela compilação de um inventário das intervenções relevantes em todo seu ciclo de vida, desde a retirada das matériasprimas necessárias à sua produção até sua disposição final no meio ambiente. Para Ferrão (1998), o termo ciclo de vida refere-se a todas as etapas e processos de um sistema de produção ou de serviços, englobando a cadeia de produção e consumo, considerando consumos de energia, matérias-primas e produtos auxiliares, aspectos relativos aos sistemas de transportes e logística, características da utilização, manuseamento, embalagem, marketing e consumo, resíduos gerados e respectiva reciclagem ou outro destino final.

As informações coletadas na ACV e os resultados de suas análises e interpretações podem ser úteis para tomadas de decisão, na seleção de indicadores ambientais relevantes para avaliação da performance de projetos e reprojetos de produtos ou processos e/ou planejamento estratégico (Chehebe, 1998). Diretamente ligada à gestão ambiental, a ACV é padronizada pela International Organization for Standardization (ISO) 14040 e suas correspondentes.

A aplicação da Avaliação do Ciclo de Vida ou Life Cycle Assessment é estruturada em quatro fases apresentadas na Figura 1. 


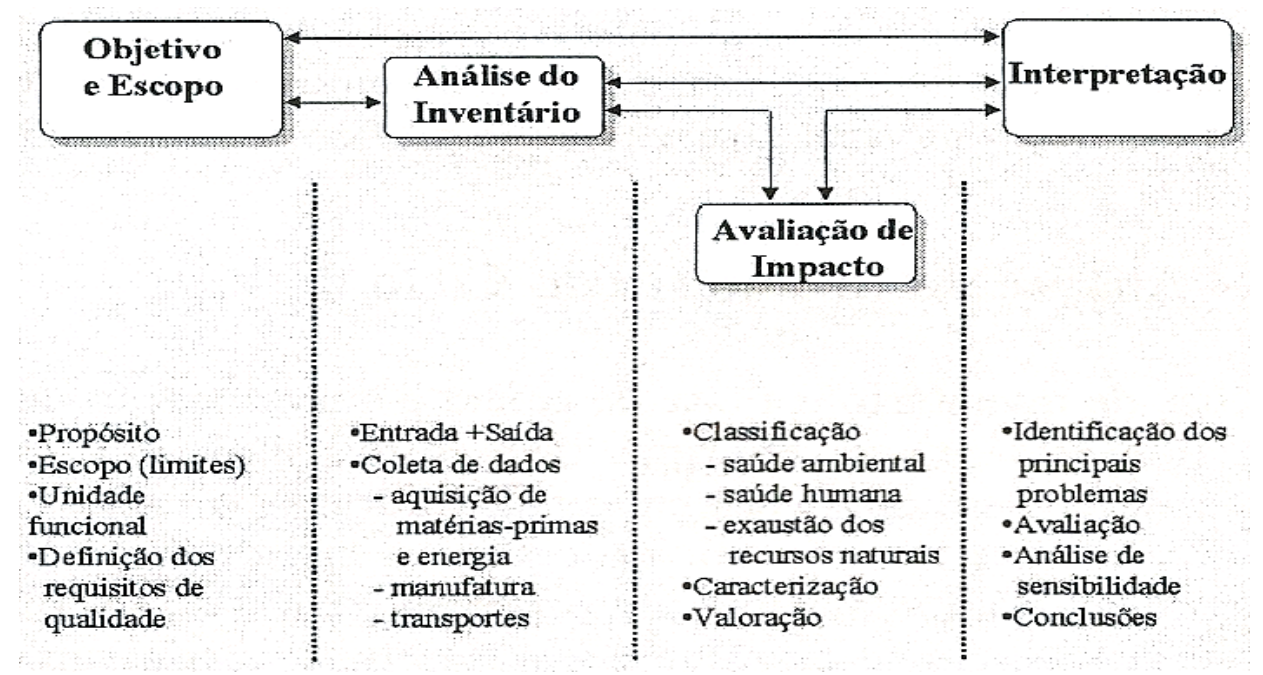

Figura 1 - Etapas de uma ACV.

Fonte: CHEHEBE, 1998.

Cada fase da ACV possui passos importantes a serem seguidos para que a avaliação possa ser confiável. Tais passos podem ser obtidos através do estudo da norma ISO 14040.

\section{OBJETIVOS}

Analisar comparativamente a produção de dois tipos de colunas de destilação (pratos e mista) objetivando verificar e indicar qual propicia menores impactos ao meio ambiente, e dessa forma, servir de alternativa para escolha do tipo de coluna ideal em termos de mitigação de impactos ambientais na produção de etanol hidratado em pequena escala.

\section{METODOLOGIA}

Seguindo as etapas descritas pela ISO 14040 e de acordo com o objetivo e o escopo do estudo, delimitou-se a fronteira do sistema a ser analisada. Após, foi realizada a coleta de dados dos fluxos englobados na fronteira do sistema para a produção de uma unidade de cada tipo de coluna (unidade funcional do sistema).

A coleta de dados mesclou três visitas ao fabricante das colunas estudadas (Limana Poliserviços, localizada em Jaguari-RS), informações obtidas do próprio fabricante mediante entrevistas e buscas em referências pertinentes. Com base nos dados coletados na elaboração do inventário do ciclo de vida, foi elaborado um fluxograma contendo as etapas do processo produtivo das colunas de destilação (Figura 2) para identificação dos fluxos de entrada e saída do processo e também para representação da fronteira do sistema. 


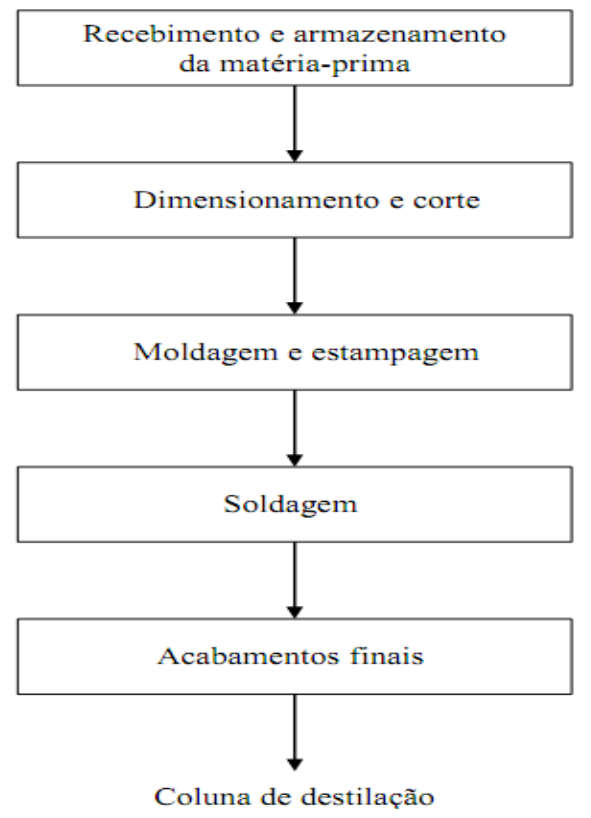

Figura 2 - Fluxograma do processo construtivo: coluna de destilação contínua de pequeno porte.

Fonte: Autor.

Apesar de grande parte das microdestilarias operarem em regime de batelada, os modelos de colunas avaliados foram projetados para operarem em regime contínuo, apostando em um eventual aumento da produção de etanol hidratado no RS, sendo apresentados na Tabela 1 alguns parâmetros fundamentais do projeto dos dois modelos de colunas.

Tabela 1 - Parâmetros de projeto das colunas de destilação

\begin{tabular}{lcc}
\hline \multicolumn{1}{c}{ Parâmetro } & Coluna de pratos & Coluna mista \\
\hline $\begin{array}{l}\text { Teor alcoólico, em massa de etanol, } \\
\text { do mosto (e em volume de etanol) }\end{array}$ & $6 \%\left(8^{\circ} \mathrm{GL}\right)$ & $6 \%\left(8^{\circ} \mathrm{GL}\right)$ \\
\hline $\begin{array}{l}\text { Teor alcoólico do etanol, em massa, } \\
\text { de saída (e em volume) }\end{array}$ & $92,5 \%\left(95,1-96^{\circ} \mathrm{GL}\right)$ & $92,5 \%\left(95,1-96^{\circ} \mathrm{GL}\right)$ \\
\hline $\begin{array}{l}\text { Fração mássica máxima de saída de } \\
\text { etanol no fundo }\end{array}$ & - & $0,5 \%$ \\
\hline
\end{tabular}

O modelo da coluna mista é a configuração do modelo de coluna de pratos e de recheio, sendo composta em sua parte superior com preenchimento de recheio randômico do tipo anel de Raschig de polipropileno e na sua parte inferior com pratos do tipo perfurados sem downcomer também chamado de prato dualflow. A coluna de pratos possui pratos do tipo válvulas. 
Os dados coletados na realização do inventário do ciclo de vida foram interpretados por meio da alocação dos mesmos no software SimaPro ${ }^{\circledR}$, sendo os resultados apresentados na forma de categorias de impactos ambientais contidas no método de avaliação de impacto escolhido (Eco-Indicador 99).

\section{RESULTADOS E DISCUSSÕES}

Os Quadros 1 e 2 apresentam os resultados da qualificação e quantificação das entradas e saídas para o processo de produção de uma coluna de destilação do tipo mista e uma coluna de destilação do tipo pratos, respectivamente. As colunas possuem capacidade de produção de etanol hidratado entre $15-30 \mathrm{~L} / \mathrm{h}$.

Com os dados do inventário alocados no SimaPro ${ }^{\circledR}$, foi realizada a comparação do processo produtivo dos tipos de colunas usadas, a partir da escolha do método de avaliação de impacto Eco-Indicador 99. Esse método expressa a interpretação dos dados de entrada do sistema por meio de categorias de impactos tais como ecotoxicidade (ecotoxicity), carcinogenia (carcinogens), radiação (radiation), mudança climática (climate change), entre outras,

A Figura 3 apresenta os resultados em termos de categorias de impacto ambiental.

Quadro 1 - Inventário de produção da coluna de destilação mista

\begin{tabular}{|c|c|c|c|c|c|}
\hline Entrada & Tipo & Quantidade & Unidade & OBS/Composição do equipamento & Fonte \\
\hline \multirow{7}{*}{ Matéria-prima } & Aço carbono (1020 STM 285) & 65,00 & $\mathrm{~kg}$ & Em média & \multirow{7}{*}{ Limana Poliserviços } \\
\hline & Aço inox em chapa (AISI 304) & 225,00 & $\mathrm{~kg}$ & Em média & \\
\hline & Vidro temperado & 2,00 & $\mathrm{~kg}$ & Em média & \\
\hline & Borracha & 3,50 & $\mathrm{~kg}$ & Em média & \\
\hline & Polipropileno & 17,00 & $\mathrm{~kg}$ & Em média & \\
\hline & Discos de corte (óxido de $\mathrm{Al}$ ) & 3,50 & $\mathrm{~kg}$ & Em média & \\
\hline & Vareta de solda $(21 \% \mathrm{Cr}$ e $12 \% \mathrm{Ni})$ & 3,50 & $\mathrm{~kg}$ & Em média & \\
\hline Água & Pluvial & 150,00 & $\mathrm{~L}$ & Lavagem (equipamentos e produtos) & \multirow{10}{*}{ considerações } \\
\hline Mão-de-obra & Processo de construção & 633,60 & $\mathrm{~h}$ & $8 \mathrm{~h} / \mathrm{dia}$ & \\
\hline Energia & Elétrica & 668,00 & kwh & Rede local & \\
\hline \multirow{4}{*}{ Equipamentos } & Tesoura mecânica & 40,00 & $\mathrm{~kg}$ & Aço carbono & \\
\hline & Esmerilhadeira & 5,00 & $\mathrm{~kg}$ & Ferro fundido, Al e polipropileno & \\
\hline & Máquina de corte por plasma & 30,00 & $\mathrm{~kg}$ & Aço carbono, inox ou alumínio (Al) & \\
\hline & Dobradeira & 150,00 & $\mathrm{~kg}$ & Aço carbono & \\
\hline \multirow{3}{*}{ (Tipo/Peso) } & Prensa & 150,00 & $\mathrm{~kg}$ & Aço carbono & \\
\hline & Calandra & 120,00 & $\mathrm{~kg}$ & Aço carbono & \\
\hline & Máquina de solda & 50,00 & $\mathrm{~kg}$ & Principalmente aço carbono e PP & \\
\hline Saídas & Tipo & Quantidade & Unidade & OBS & Fonte \\
\hline Produto & Coluna de destilação mista & 1,00 & unidade & $15-30 \mathrm{~L} / \mathrm{h}$ & \multirow{4}{*}{ Limana Poliserviços } \\
\hline \multirow{3}{*}{ Resíduos sólidos } & $\begin{array}{c}\text { Retalhos de aço inox } \\
\text { Retalhos de aço carbono }\end{array}$ & $\begin{array}{c}17,00 \\
4,50\end{array}$ & $\begin{array}{l}\mathrm{kg} \\
\mathrm{kg}\end{array}$ & $\begin{array}{c}\text { Armanezados/coletados por empresa } \\
\text { credenciada }\end{array}$ & \\
\hline & Discos de corte usados & 1,30 & $\mathrm{~kg}$ & & \\
\hline & Vareta de solda usada & 1,90 & $\mathrm{~kg}$ & & \\
\hline
\end{tabular}


Quadro 2 - Inventário de produção da coluna de destilação de pratos

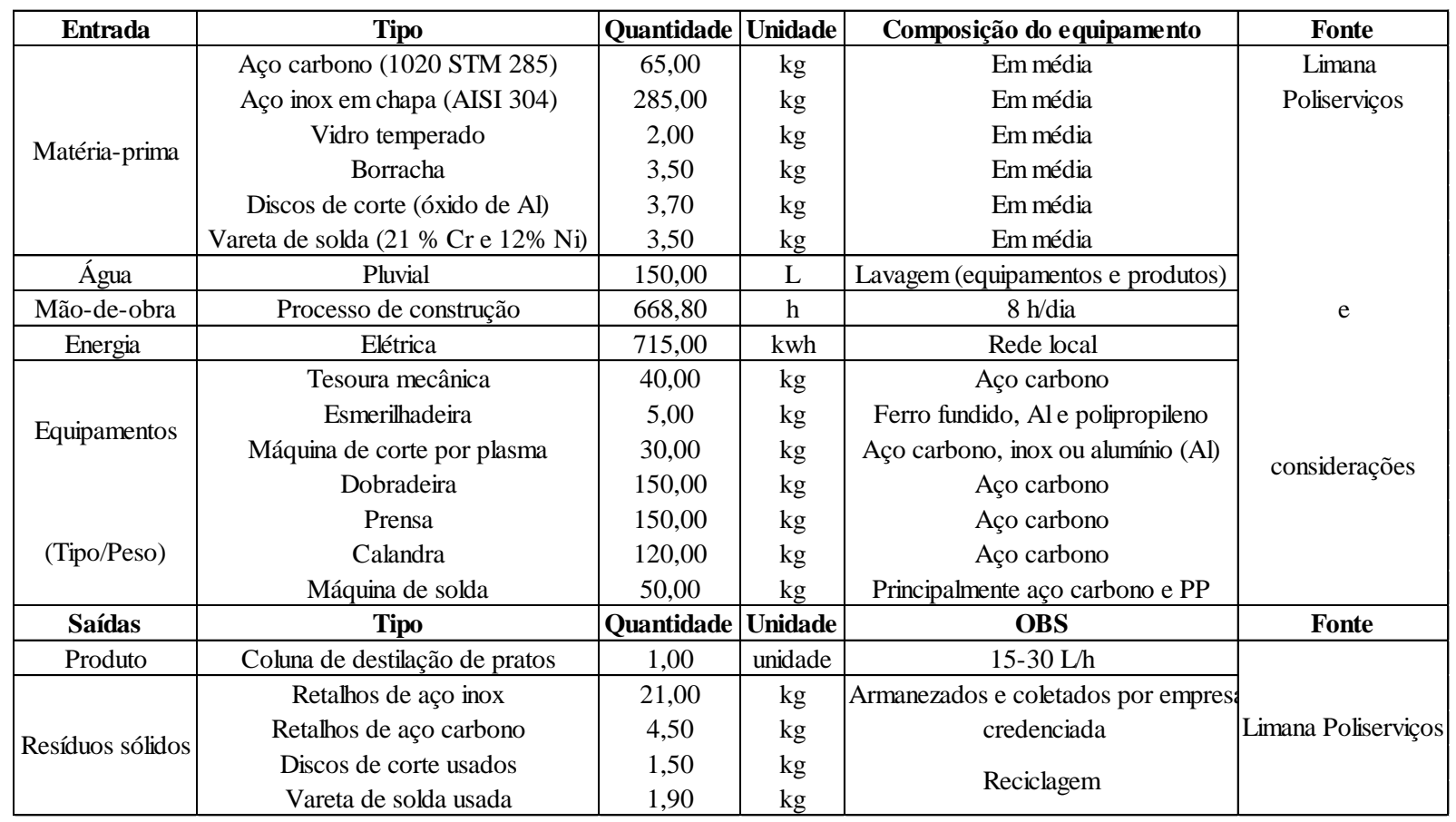

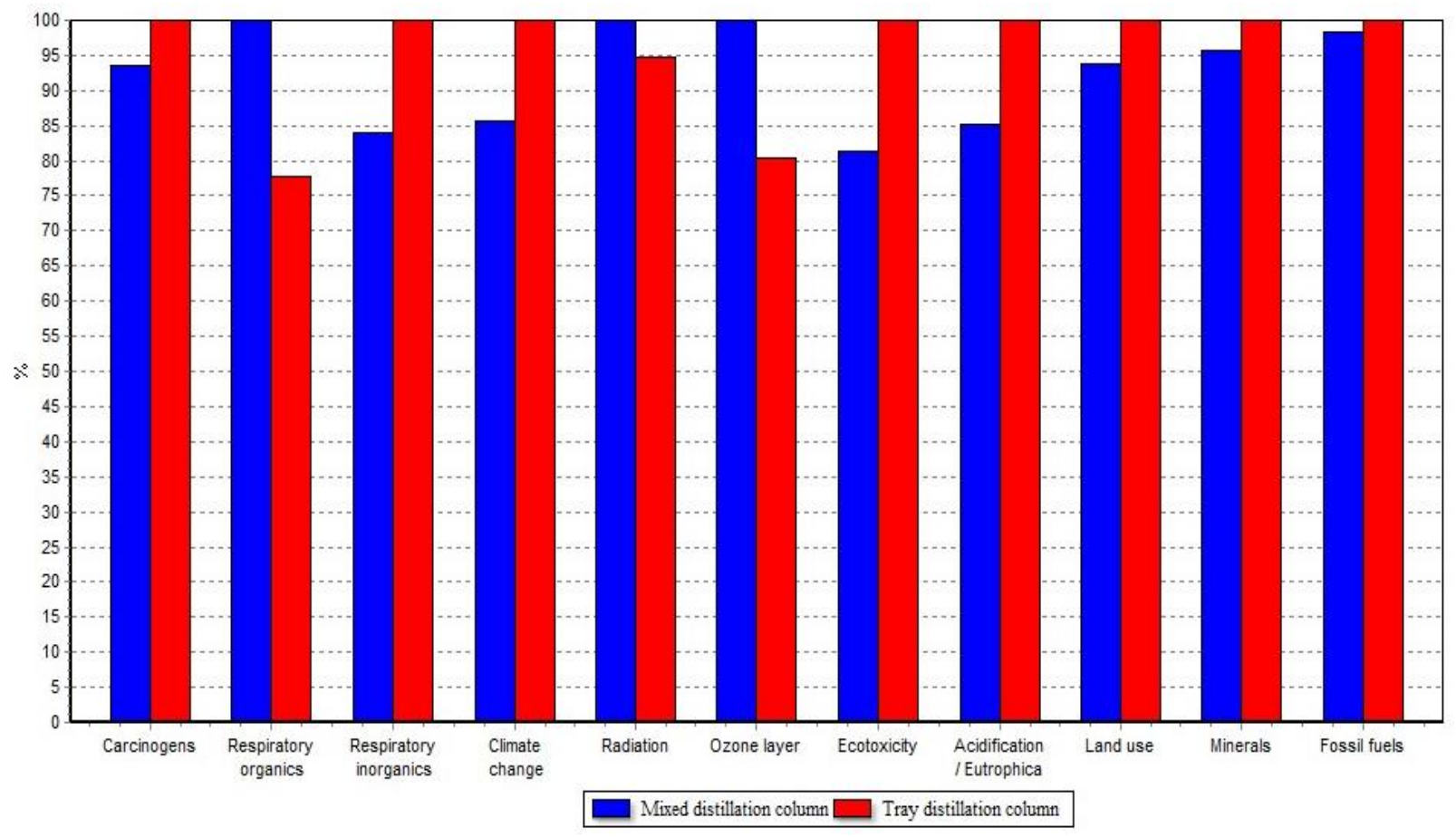

Figura 3 - Avaliação de impactos da produção dos modelos de colunas. 
O modelo de coluna de destilação por pratos (tray distillation column) apresentou maior porcentagem de contribuição em 8 das 11 categorias de impacto, ou seja, pode-se concluir que esse tipo de coluna de destilação implica em maiores impactos ao meio ambiente em comparação com a coluna de destilação do tipo mista (mixed distillation column).

Apesar do fato de a diferença de contribuição não ser elevada, é pertinente tal estudo e resultado, tendo em vista que pequenas diferenças de produção e uso de materiais podem surtir efeitos positivos e/ou negativos para o meio ambiente que muitas vezes são desconsiderados em um processo de construção, devido à pequena diferença mássica e/ou energética que apresentam.

O uso de polipropileno (PP), para construção da coluna mista (confecção do recheio), implica em menores impactos ao meio ambiente em detrimento de um maior uso de aço inox para construção da coluna de pratos. Para confecção da coluna de pratos foram usados $285,00 \mathrm{~kg}$ de aço inox enquanto que para coluna mista foram usados $225,00 \mathrm{~kg}$, pois há necessidade de confecção de um maior número de pratos para este tipo de coluna, pois o modelo misto tem a seção superior composto por recheio.

O PP foi usado apenas para construção da coluna mista $(17,00 \mathrm{~kg})$, mas essa quantidade implicou em menos impactos em relação à diferença de $60,00 \mathrm{~kg}$ de aço inox a mais, usado para construção da coluna de pratos. Ainda, pelo fato da moldagem/construção de um maior número de pratos, há um maior consumo de energia elétrica para construção da coluna de destilação de pratos.

\section{CONCLUSÃO}

O modelo de coluna de destilação por pratos apresentou maiores contribuições de impactos do que o modelo de coluna mista, com maiores porcentagens em 8 das 11 categorias de impacto. Por isso, a escolha pela instalação de uma coluna tipo mista, em uma microdestilaria, é indicado em termos de mitigação de impactos ambientais, servindo também de complemento para uma análise econômica e energética.

Tais resultados evidenciam a importância de uma análise qualitativa e quantitativa de um processo, destacando a ACV como uma importante ferramenta para avaliação e identificação de impactos ambientais.

\section{REFERÊNCIAS}

BEN (BALANÇO ENERGÉTICO NACIONAL). Relatório Final - Ano Base 2011. Elaborado pelo Ministério de Minas e Energia (MME) e Empresa de Pesquisa Energética (EPE). Brasília, Brasil, 2012, 282 p.

CASTRO, L. A. S.; EMYGDIO, B. M.; ABRANTES, V. L.; ROCHA, N. E. M. Acessos de bata-doce do banco ativo de germoplasma da Embrapa Clima Temperado, com potencial de 
produção de biocombustível. Documentos 258, Pelotas, p. 1-23, 2008, ISSN 1806-9193.

CHEHEBE, J. R. B. Análise do Ciclo de Vida de Produtos - Ferramenta Gerencial da ISO 14000. Rio de Janeiro. Ed. Qualitymark Ltda, 1998, 104 p.

FERRÃO, P. C. Introdução à gestão ambiental - A avaliação do ciclo de vida de produtos. Lisboa. Ed. IST Press, 1998, 219 p.

IEA (INTERNATIONAL ENERGY AGENCY). Renewables Information. 2012. 497 p. Disponível em: <http://www.iea.org/media/training/presentations/statisticsmarch/RenewablesInformation.pdf $>$. Acesso em: 10 set. 2013.

ISO 14040. Environmental management - Life Cycle Assessment - Principles and framework. 2006, $20 \mathrm{p}$.

MENDONÇA, R. M. L. Avaliação do Ciclo de Vida do carbono na queima de biodiesel à base de óleo de soja. 2007. 110 p. Dissertação (Mestrado em Ciências Mecânicas) - Universidade de Brasília, Brasília, 2007.

ORTEGA, E.; WATANABE, M.; CAVALETT, O. A produção de etanol em micro e minidestilarias. In: CORTEZ, L. A. B.; LORA, E. E. S.; GÓMEZ, E. O. (Org.). Biomassa para energia. Ed. UNICAMP, 2008. Cap. 14, p. 475-491.

UFSM (UNIVERSIDADE FEDERAL DE SANTA MARIA). Avaliação da Viabilidade da Produção de Álcool a Partir de Cana-de-açúcar e Mandioca em Pequenas Unidades Camponesas de Produção. $4^{\circ}$ Relatório Parcial, Santa Maria, 2010, 6p.

ÚNICA (UNIÃO DA INDÚSTRIA DE CANA-DE-AÇÚCAR). Disponível em: < http://www.unica.com.br/faq/>. Acesso em: 20 jun. 2013.

WEIDEMA, B. P.; MEEUSEN, M. J. G. Agricultural data for life cycle assessments. Agricultural Economics Research Institute (LEI), The Hague. Report 2.00.01, ISBN 90-5242563-9; Price NLG.120, v. 1, 2000, 195 p. Disponível em: < http://www.imamu.edu.sa/topics/IT/IT\%206/Agricultural\%20data\%20for\%20Life\%20Cycle \%20 Assessments.pdf >. Acesso em: 22 set. 2013. 